\title{
RETRACTED ARTICLE: Synthesis and characterization of CuO nanoparticles and evaluation of their bactericidal and fungicidal activities in cotton fabrics
}

\author{
Devarajan Alagarasan ${ }^{1} \cdot$ A. Harikrishnan ${ }^{2} \cdot$ M. Surendiran ${ }^{2} \cdot$ Karuppusamy Indira $^{3} \cdot$ Amany Salah Khalifa $^{4}$. \\ Basem H. Elesawy ${ }^{5}$
}

Received: 7 April 2021 / Accepted: 28 August 2021 / Published online: 12 September 2021

(c) King Abdulaziz City for Science and Technology 2021

The Editor-in-Chief and the publisher have retracted this article. The article was submitted to be part of a guest-edited issue. An investigation by the publisher found a number of articles, including this one, with a number of concerns, including but not limited to compromised editorial handling and peer review process, inappropriate or irrelevant references or not being in scope of the journal or guest-edited issue. Based on the investigation's findings the Editor-inChief therefore no longer has confidence in the results and conclusions of this article.

The authors Devarajan Alagarasan, A. Harikrishnan, M. Surendiran, Karuppusamy Indira disagree with this retraction. The authors Amany Salah Khalifa and Basem H. Elesawy have not responded to correspondence regarding this retraction. The online version of this article contains the full text of the retracted article as Supplementary Information.

Electronic supplementary material The online version of this article (https://doi.org/10.1007/s13204-021-02054-5) contains supplementary material, which is available to authorized users.

Publisher's Note Springer Nature remains neutral with regard to jurisdictional claims in published maps and institutional affiliations.

Springer Nature or its licensor (e.g. a society or other partner) holds exclusive rights to this article under a publishing agreement with the author(s) or other rightsholder(s); author self-archiving of the accepted manuscript version of this article is solely governed by the terms of such publishing agreement and applicable law.

Devarajan Alagarasan

alagarasan@iisc.ac.in; alagarasanph@gmail.com

$\triangle$ A. Harikrishnan

harich4@gmail.com; sschemsurender@gmail.com

$\triangle$ Karuppusamy Indira

indirakaruppusamy@gmail.com

1 Department of Physics, Indian Institute of Science, Bengaluru 560012, India

2 Department of Chemistry, School of Arts and Sciences, Vinayaka Mission's Research Foundation, Aarupadai Veedu (VMRF-AV) Campus, Paiyanoor, Chennai, Tamil Nadu 603104, India

3 Department of Chemistry, M. Kumarasamy College of Engineering, Karur, Tamil Nadu 639113, India

4 Department of Clinical Pathology and Pharmaceutics, College of Pharmacy, Taif University, P.O. Box 11099, Taif 21944, Saudi Arabia

5 Department of Pathology, College of Medicine, Taif University, P.O. Box 11099, Taif 21944, Saudi Arabia 